\title{
Analysis on the Interference Assembly of Camshaft With Knurled Tube and Cam
}

\section{Xiaoming Huang ( $\nabla$ hxm2552@163.com )}

Ningbo Shenglong Group Co., Ltd., Ningbo, 315000, China)

\section{Weitao Sun}

Mechatronics Engineering Department, Binzhou University, Binzhou 256603, China

Xiaoliang Liu

Mechatronics Engineering Department, Binzhou University, Binzhou 256603, China

\section{Yucan Wang}

Mechatronics Engineering Department, Binzhou University, Binzhou 256603, China

Jin Xing

Mechatronics Engineering Department, Binzhou University, Binzhou 256603, China Hailin Bi

Mechatronics Engineering Department, Binzhou University, Binzhou 256603, China

\section{Yuqian Wang}

Mechatronics Engineering Department, Binzhou University, Binzhou 256603, China

\section{Wentao You}

Mechatronics Engineering Department, Binzhou University, Binzhou 256603, China

\section{Research Article}

Keywords: Interference assembly, Camshaft, Knurling, Joining force, Metal rheology, Connection strength

Posted Date: February 12th, 2021

DOl: https://doi.org/10.21203/rs.3.rs-218258/v1

License: (c) (1) This work is licensed under a Creative Commons Attribution 4.0 International License. Read Full License

Version of Record: A version of this preprint was published at The International Journal of Advanced Manufacturing Technology on August 3rd, 2021. See the published version at https://doi.org/10.1007/s00170-021-07783-z. 


\title{
Analysis on the interference assembly of camshaft with knurled tube and cam
}

\author{
Xiaoming Huang ${ }^{1,2}$, Weitao Sun ${ }^{1}$, Xiaoliang Liu ${ }^{1}$, Yucan Wang ${ }^{1}$, Jin Xing ${ }^{1}$, Hailin $\mathrm{Bi}^{1}$, \\ Yuqian Wang ${ }^{1}$, Wentao You ${ }^{1}$ \\ (1 Mechatronics Engineering Department, Binzhou University, Binzhou 256603, China \\ 2 Ningbo Shenglong Group Co., Ltd., Ningbo, 315000, China)
}

\begin{abstract}
Interference joint is one of the most advanced assembly methods for camshaft. In this paper, the mechanism of camshaft interference assembly is analyzed by thick-wall cylinder model. Joining/tortion experiments are done to estimate the joining force and connection strength. The relationship between the torque capacity, joining force and interference of the camshaft is established by the experiment results. Joining force linear increase with the interference, and torque exponential increase with it. The plastic deformation characteristics of knurled teeth on the tube during the joining process are obtained by metallographic observation. The results reveal the metal line changes continuously of the knurled tube. The knurled tooth tip turns over after joining. And elastic limit would be reached in the extrusion region.
\end{abstract}

Keywords: Interference assembly; Camshaft; Knurling; Joining force; Metal rheology; Connection strength

Corresponding Author: Xiaoming Huang,

E-mail address: hxm2552@163.com

\section{Introduction}

As the key part of the engine valve, camshaft has an important influence on the volume of intake air, dynamic performance, and gas emission of the engine [1]. Camshaft can be sorted into two categories: integral type and assembled type. The assembly camshaft consists of cam and shaft. Assembly camshaft has significant advantages comparing with casting, powder sintering, and forging integral camshaft, such as weight reduction, material optimization, production cost, and energy saving. 
Recent developments in lightweight vehicles have heightened the need for assembly camshaft $[2,3]$. However, lacking of high machining reliability has been problem in the industrial production for many years [4].

A mass of connection methods have been studied in recent years, including shrink fit assembling, welding, bonding, mechanical expanding joint, and hydraulic expanding joint [5]. Shrink fit assembling, welding would lead to undesired thermal expansion of cam. This would make it difficult to control the assembly accuracy and result in uncertainty of the joint reliability [6]. Bonding, mechanical expanding, and hydraulic expanding joint could not supply enough connection strength for requirements of high power engines. Interference assembly of knurled cam and tube has been widely used in camshafts manufacturing because of high connection strength, and no thermal deformation etc $[7,8]$.

The studies on the assembly camshaft mainly focus on two aspects: the joining force and the connection strength. The joining force and connection strength of the assembly camshaft depends on many factors, including interference, geometric parameters and material properties [9, 10]. For example, the assembly camshaft of 100Cr6 cam and AlMgSi tube were studied by Kleditzsch S et al. [11, 12]. The results show that the tube chamfer angle has a crucial influence on the joining forces as well as the push out forces. Larger shaft chamfer angles lead to lesser joining force. The researchers think that the cutting joining is made possible because of larger shaft chamfer angles. Zhang P et al. [13] investigated the relationship between independent camshaft assembly variables and the joining force. The optimal combinations of knurling tooth height, tooth angle, and feed are concluded for lesser joining force and larger connection strength. Stress between cam and shaft decides the operation of assembly camshaft, such as connection strength and fatigue behaviour. So, Sen S et al. $[14,15]$ studied the stress distribution in relation to the ratio of contact length/diameter using the elastic/plastic FE model.

In generally, larger interference will lead to more connection strength [16]. However, too much interference would cause bursting failure of the cam. The plastic instability is related to strain hardening exponent, plastic anisotropy parameter, and 
strength coefficient $[17,18]$. In addition, process parameters, such as feed speed, are significant factors on the initiation of failure $[19,20]$.

It is almost certain that the interference has an important influence on the connection strength. It determines the joining force and working reliability of camshaft. However, for the camshaft with knurled tube and cam, the relationship between the interference and the joining force as well as connection strength is not analyzed fully. In this paper, the influence of interference on the joining force and connection strength is discussed by theory analysis. Then, the values of joining force and connection strength of five groups of camshaft with different interference are obtained and studied by joining and torsion experiment. Metal plastic deformation, stress and strain of knurled tube are analyzed systematically by metallographic observation and FEM.

\section{Mechanism of camshaft interference joining}

Axial and radial section of the camshaft are shown in Fig. 1. Axial rectangular convex-concave grooves are on the inside surface of the cam. A series of knurled teeth are on the external surface of the hollow tube with a direction perpendicular to axial direction. Concave/convex mosaic is generated by interference joining between tube and cam. This knurling interference connection can provide both shear and friction resistance for working camshaft.

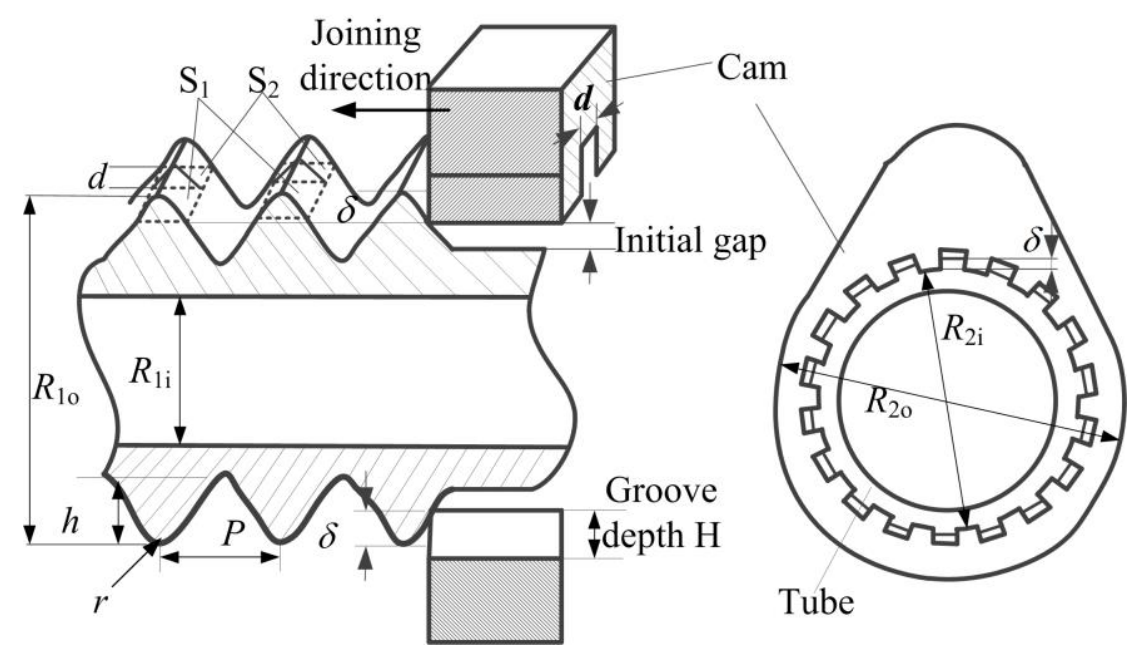

Fig. 1 Axial and radial section of camshaft 
2.1 Joining force and connection strength of camshaft

The joining force $F$ includes two parts: one is friction $F_{f}$ and the other is shear force $F_{s}$.

$$
F=F_{f}+F_{s}
$$

The friction force is as follows:

$$
F_{f}=\mu \cdot P_{j} \cdot S_{1}
$$

where $\mu$ is the friction coefficient, $S_{1}$ is the interference as shown in Fig. $1 . P_{j}$ is the contact pressure between cam and tube. It changes with time and location in the joining process because of the three-dimensional structure of camshaft. Shear is plastic deformation, which would be discussed in section 2.3.

The connection strength $T$ is also composed of two parts, one is the friction torque $T_{f}$ caused by contact pressure, the other is the shear torque $T_{s}$ caused by knurled teeth of tube and grooves of cam according to Eqs. 3, 4 and 5.

$$
\begin{gathered}
T=T_{f}+T_{s} \\
T_{f}=P \cdot S_{1} \\
T_{s}=f\left(P, \tau, S_{2}\right)
\end{gathered}
$$

where $P$ is contact pressure between cam and tube after joining, $\tau$ is shear coefficient of cam. $S_{2}$ is determined by the distance $d$ between convex and concave grooves of cam as shown in Fig. 1.

2.2 Pressure and displacement of the cam and tube for elastic deformation

From the above analysis, we can see that contact pressure between tube and cam is the key factor affecting joining force and connection strength. $P$ is related to the interference and structure of camshaft.

To simplify the model, the thick-wall cylinder model is used to analyze the joining process[21]. According to mechanics assumption, the thick wall cylinder model is valid if $\mathrm{K}_{1}=R_{\mathrm{o}} / R_{\mathrm{i}} \geq 1.2$ and $\mathrm{K}_{2}=R_{\mathrm{o}} / t \leq 10$. Where $R_{\mathrm{o}}, R_{\mathrm{i}}$ and $t$ is outside diameter, inside diameter and thickness of the wall cylinder. The cam and tube are recorded as thick wall cylinder 1 and 2, respectively. The inside and outside diameters 
of the cam are $R_{1 \mathrm{i}}$, and $R_{10}$. For cam: $\mathrm{K}_{11}=35 / 24.65=1.4 \geq 1.2, \mathrm{~K}_{12}=35 / 5.2=6.7<10$. For tube: $K_{21}=24.3 / 18.7=1.3 \geq 1.2, K_{22}=24.3 / 2.8=8.6<10$. The thick wall cylinder model is available for them.

During the joining process, the expansion pressure $P_{1 i}$ acted on the inner surface of the cam. According to the solution of elastic mechanics, the stress and displacement of cam are presented in Eq. 6 when the cam is simplified to a cylinder:

$$
\left\{\begin{array}{l}
u(r)=\frac{1-\mu_{1}}{E_{1}} \frac{\left(R_{1 i}^{2} P_{1 i}-R_{1 o}^{2} P_{1 o}\right) r}{R_{1 o}^{2}-R_{1 i}^{2}}+\frac{1+\mu_{1}}{E_{1}} \frac{R_{1 i}^{2} R_{1 o}^{2}\left(P_{1 i}-P_{1 o}\right)}{\left(R_{1 o}^{2}-R_{1 i}^{2}\right) r} \\
\sigma_{r}(r)=\frac{R_{1 i}^{2} p_{1 i}-R_{10}^{2} P_{1 o}}{R_{1 o}^{2}-R_{1 i}^{2}}-\frac{R_{1 i}^{2} R_{10}^{2}\left(P_{1 i}-P_{1 o}\right)}{\left(R_{1 o}^{2}-R_{1 i}^{2}\right) r^{2}} \\
\sigma_{\theta}(r)=\frac{R_{1 i}^{2} P_{1 i}-R_{10}^{2} P_{1 o}}{R_{1 o}^{2}-R_{1 i}^{2}}+\frac{R_{1 i}^{2} R_{1 o}^{2}\left(P_{1 i}-P_{1 o}\right)}{\left(R_{1 o}^{2}-R_{1 i}^{2}\right) r^{2}}
\end{array}\right.
$$

where, $\sigma_{r}(r)$ and $\sigma_{\theta}(r)$ are radial stress and circumferential stress respectively; $u(r)$ is radial displacement, $E_{1}$ and $\mu_{1}$ are the elastic modulus and Poisson's ratio of the cam. When $r=R_{1 \mathrm{i}}$, the stress and displacement are:

$$
\left\{\begin{array}{l}
u\left(R_{1 i}\right)=\left(\frac{1-\mu_{1}}{E_{1}} \frac{R_{1 i}^{3}}{R_{1 o}^{2}-R_{1 i}^{2}}+\frac{1+\mu_{1}}{E_{1}} \frac{R_{1 i} R_{1 o}^{2}}{\left(R_{1 o}^{2}-R_{1 i}^{2}\right)}\right) P_{1 i} \\
\sigma_{r}\left(R_{1 i}\right)=-P_{1 i} \\
\sigma_{\theta}\left(R_{1 i}\right)=\left(\frac{R_{10}^{2}+R_{1 i}^{2}}{R_{1 o}^{2}-R_{1 i}^{2}}\right) P_{1 i}
\end{array}\right.
$$

The stress and displacement of tube when $r=R_{20}$ is:

$$
\left\{\begin{array}{l}
u\left(R_{2 o}\right)=-\left(\frac{1-\mu_{2}}{E_{2}} \frac{R_{2 o}^{3}}{R_{2 o}^{2}-R_{2 i}^{2}}+\frac{1+\mu_{2}}{E_{2}} \frac{R_{2 i}^{2} R_{2 o}}{\left(R_{2 o}^{2}-R_{2 i}^{2}\right)}\right) P_{2 o} \\
\sigma_{r}\left(R_{2 o}\right)=-P_{2 o} \\
\sigma_{\theta}\left(R_{2 o}\right)=\frac{R_{2 o}^{2}+R_{2 i}^{2}}{R_{2 i}^{2}-R_{2 o}^{2}} P_{2 o}
\end{array}\right.
$$

The inside and outside diameters of the hollow tube are $R_{2 \mathrm{i}}$ and $R_{20}$ respectively, and the elastic modulus and Poisson's ratio are $E_{2}$ and $\mu_{2}$. The outside diameter of the steel pipe is equal to the inside diameter of the cam after interference joining, $R_{1 \mathrm{i}}=R_{2 \mathrm{o}}$. The radial pressure between cam and tube is $P_{1 \mathrm{i}}=P_{20}=P$, which is closely related to the stress state of the contact area.

The interference between the cam and the tube as follows:

$$
\delta=u\left(R_{1 i}\right)+u\left(R_{2 o}\right)
$$

2.3 Plastic deformation of the camshaft in the joining process 
The plastic deformation, strain hardening and failure criterion of the material are critical for the joining process. The plastic joining force $F_{\mathrm{s}}$ depends on the real contact area $S_{1}$, the contact pressure $P$, and the coefficient $X_{f, c}$ between tube and cam as described in reference[22].

$$
F_{s}=f\left(S_{1}, P, X_{f, c}, \tau\right)
$$

The contact area $S_{1}$ between knurled tube and grooved cam, is based on the knurled tooth profile and interference as show in Fig. 1. The larger the interference, the larger the contact area $S_{1}$. The coefficient $X_{f, c}$ varies depending on time and location during joining process because of the both 3D structure of tube and cam.

At the same time, large plastic deformation can also lead to material hardening[23]. Strain rate, displacement rate and stress rate all affect the hardening coefficient of the material[24]. The shear strain could be revealed as:

$$
\varepsilon=\left[D_{1}+D_{2} \exp \left(D_{3} \sigma^{*}\right)\right]\left[1+D_{4} \ln ^{\mathrm{g}}{ }^{*}\right]
$$

where $D_{1}-D_{4}$ are failure parameters of material; $\sigma^{*}$ and $\stackrel{\mathrm{g}}{\varepsilon}{ }^{*}$ are parameter of stress state and strain rate state.

For the joining process of camshaft, the stress and strain of each position are variable with time. It is very difficult to calculate the joining force and connection strength for real camshaft using analytical method. This is because of the coupling interaction of elastic and plastic deformation in the axial direction, radial direction and circumferential direction. However, the above analysis provides a theoretical basis for the subsequent experimental results and FEM results.

\section{Experiment and FEM model}

\subsection{Experiment set up}

Joining process is performed on SHT4304 electro-hydraulic machine. Static torque capacity is obtained by static torsion system (SLPCL). Joining speed and rotation speed are set as $40 \mathrm{~mm} / \mathrm{min}$ and $10^{\circ} / \mathrm{min}$ at room temperature. In the joining process, a few cams are fitted onto the tube in order, in which each cam is independent. In our case, the cam material is GGr15 and the tube material is E355. 
The geometric parameters of the cam and tube are shown in Fig. 1 and Table 1. The number of knurled teeth is nine for tube, which corresponding to one cam. The values in Table 1 are empirical parameters used in industry manufacturing production. And they are taken as reference geometric parameter.

The interference between the cam and the shaft defined as $\delta=\left(R_{1 o}-R_{2 i}\right) / 2$. Different interference are controlled through different inside diameter of cam $R_{2 \mathrm{i}}$. $R_{2 \mathrm{i}}$ $=24.2 \mathrm{~mm}, 24.1 \mathrm{~mm}, 24.0 \mathrm{~mm}, 23.9 \mathrm{~mm}, 23.8 \mathrm{~mm}$ and 23.7 respectively. There are six groups of different interference. They are $\delta=0.05 \mathrm{~mm}, 0.1 \mathrm{~mm}, 0.15 \mathrm{~mm}, 0.2 \mathrm{~mm}$, $0.25 \mathrm{~mm}$ and $0.3 \mathrm{~mm}$. Each group has four cams for joining, in which the interference between cam and tube are constant to ensure the experiment reliability.

Table 1 Geometric parameter of tube and cam

\begin{tabular}{|c|c|c|c|c|c|c|c|c|c|}
\hline \multicolumn{5}{|c|}{ Tube } & \multicolumn{4}{|c|}{ Cam } & \multirow{3}{*}{ Interference $\delta$} \\
\hline \multirow[t]{2}{*}{$R_{1 \mathrm{i}}$} & \multirow[t]{2}{*}{$R_{1 \mathrm{o}}$} & \multicolumn{3}{|c|}{ Knurling teeth } & \multirow{2}{*}{$R_{2 \mathrm{i}}$} & \multirow{2}{*}{$R_{2 \mathrm{o}}$} & \multicolumn{2}{|c|}{ Grooving parameter } & \\
\hline & & $h$ & $r$ & $P$ & & & $d$ & $H$ & \\
\hline 18.7 & 24.3 & 0.65 & 0.16 & 1.57 & 23.9 & 39.0 & 1.02 & 0.35 & 0.25 \\
\hline
\end{tabular}

After joining, the camshaft is cut in axial and radial direction by A1100S wire-electrode cutting machine. Then, connection details are analyzed using metallographic microscope.

\subsection{FEM modeling}

The joining process is studied by using the FEM software ABAQUS. The cam was defined as rigid in the FEM model because the hardness ratio between GCr15 and E355 approximately is 3/1. Cam has a hardness of HRC 64.2, which is much higher than that of tube. The basic mechanical property parameters of the shaft and cam are listed in Table 2 [9]. In the FE model, the stress/strain curve of E355 is used in the calculation process, which was obtained using the tensile experiment values as shown in Fig. 2. 


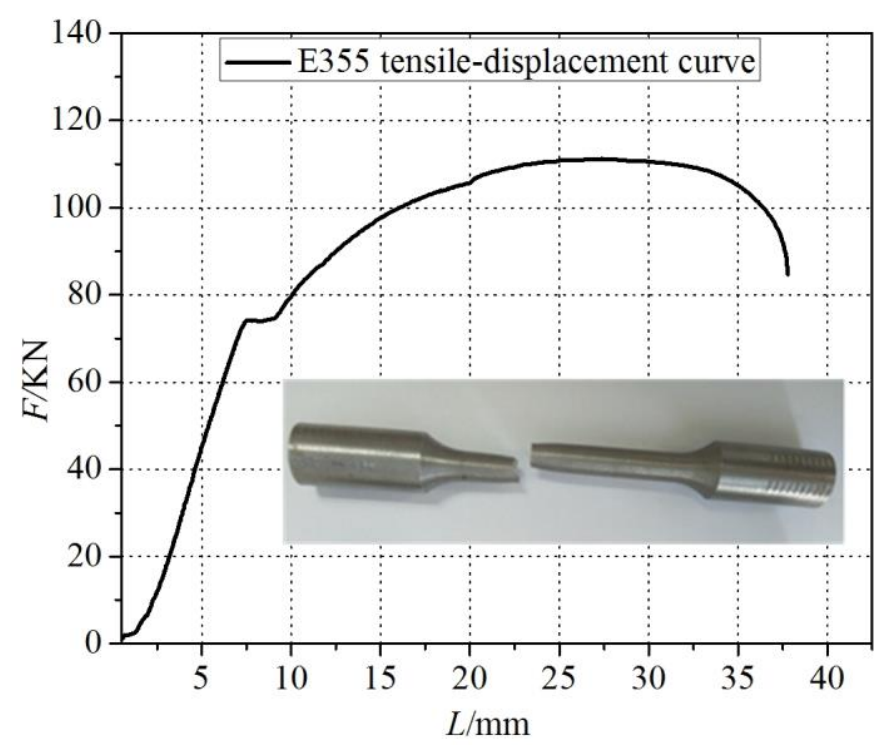

Fig. 2 Engineering load / displacement curve

Table 2 Basic mechanical properties of E355 and GCr15 materials

\begin{tabular}{ccccc}
\hline Material & $\begin{array}{c}\text { Yield strength } \\
(\mathrm{MPa})\end{array}$ & $\begin{array}{c}\text { Modulus of elasticity } \\
(\mathrm{GPa})\end{array}$ & $\mu$ & HRC \\
\hline E355 & 530 & 198 & 0.3 & 21.3 \\
GCr15 & 632 & 206 & 0.28 & 64.2 \\
\hline
\end{tabular}

Only quarter of one tube knurled tooth is modeled due to the rotational symmetric body. A coupled Euler-Lagrange analysis is applied in the model which is suitable for large deformation. The cam is set as fixing constraint. The axial displacement is applied to the tube to simulate the joining process. The Coulomb friction model is adopted in the FEM simulation. Friction coefficient of joining without lubrication is $0.125[25,26]$. C3D8R mesh is introduced to discrete the tube.

\section{Results and discussion}

4.1 Effect of interference on joining force and connection strength

Joining force and connection strength are determined by both elastic deformation and plastic flow of knurled material. Detailed information about joining force and connection strength under different interference between tube and cam are listed in Table 3. When interference between cam and tube is $0.3 \mathrm{~mm}$, the cam will crack and no valid joining force is obtained. This means that the cam would be at risk of fracture in the regions of stress concentration when the interference is beyond certain 
threshold.

Table 3 Joining force and torsion in experiment

\begin{tabular}{ccccc}
\hline$\delta(\mathrm{mm})$ & No. & $R_{2 \mathrm{i}}(\mathrm{mm})$ & $F(\mathrm{KN})$ & $T(\mathrm{Nm})$ \\
\hline \multirow{5}{*}{0.05} & $1 \#$ & 24.21 & 8.24 & 358 \\
& $2 \#$ & 24.23 & 7.46 & 357 \\
& $3 \#$ & 24.21 & 7.83 & 384 \\
& $4 \#$ & 24.19 & 9.27 & 421 \\
\hline \multirow{5}{*}{0.1} & $5 \#$ & 24.12 & 11.93 & 522 \\
& $6 \#$ & 24.11 & 12.08 & 543 \\
& $7 \#$ & 24.11 & 12.43 & 602 \\
& $8 \#$ & 24.13 & 11.96 & 581 \\
\hline \multirow{5}{*}{0.15} & $9 \#$ & 24.03 & 13.25 & 566 \\
& $10 \#$ & 24.01 & 13.92 & 593 \\
& $11 \#$ & 24.02 & 13.96 & 637 \\
& $12 \#$ & 23.98 & $\mathbf{1 4 . 0 7}$ & $\mathbf{6 5 4}$ \\
\hline \multirow{5}{*}{0.2} & $13 \#$ & 23.80 & 16.92 & 711 \\
& $14 \#$ & 23.81 & 16.84 & 678 \\
& $15 \#$ & 23.83 & 16.73 & 664 \\
& $16 \#$ & 23.80 & 17.45 & 623 \\
\hline \multirow{6}{*}{0.25} & $17 \#$ & 23.69 & 21.17 & 675 \\
& $18 \#$ & 23.67 & 21.33 & 726 \\
& $19 \#$ & 23.71 & 20.54 & 659 \\
& $20 \#$ & 23.71 & 20.93 & 696 \\
\hline
\end{tabular}

Joining forces of 12\# experiment are plotted in Fig. 3 when the interference is $0.15 \mathrm{~mm}$. Joining forces wave increasing is observed for the joining process between cam and tube. After one knurled tooth is pushed down completely, the joining force began to decrease because of a gap existed between two neighboring teeth. The joining force gradually increased up to $14.07 \mathrm{KN}$. 


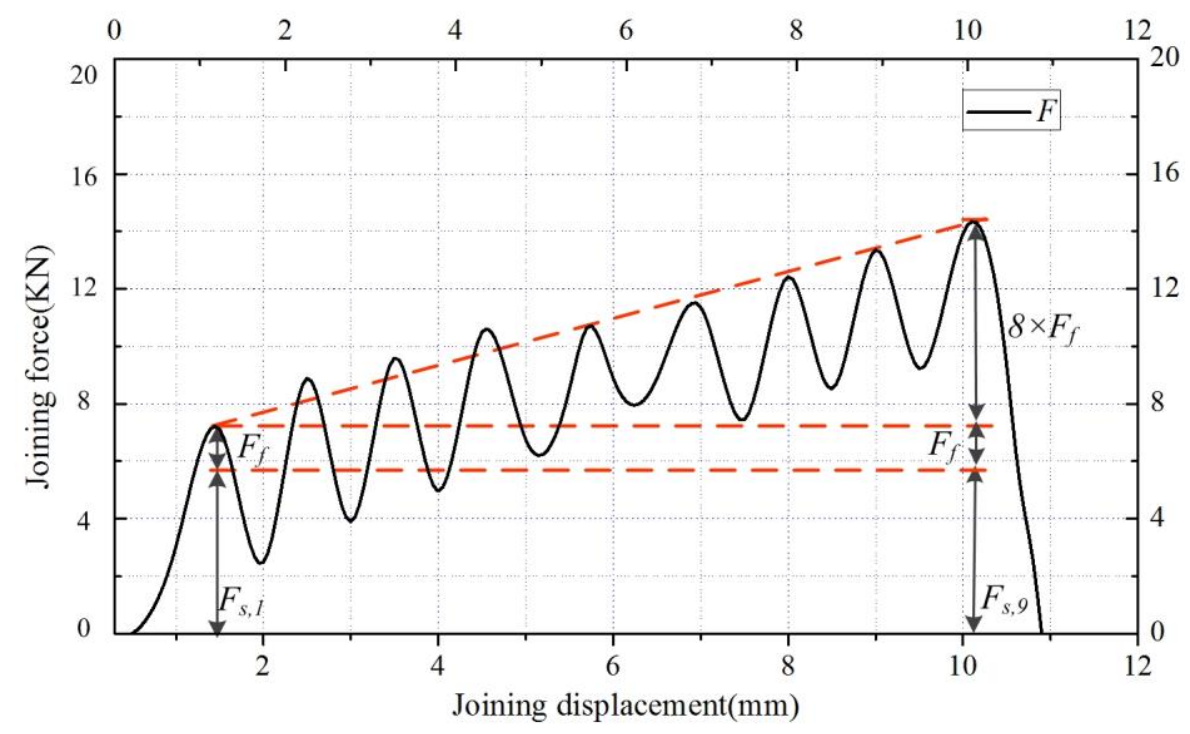

Fig. 3 Joining force curve of 12\# experiment

As explicated in section 2, the joining force is composed by friction force and shear force. The polynomial interpolation can be used to describe the increasing law of the joining force with the joining length as the independent variable:

$$
F(l)=\sum_{i}^{9} F_{i}(l)=\sum_{i=1}^{9} F_{f, i}(l)+F_{s, i}(l)
$$

Where $l$ is the joining length, $i$ is the knurled tooth number of joining. There are 9 knurled teeth in total on the tube for each cam. For example, $\sum_{i=1}^{9} F_{f, 9}(l)$ stand for the friction force of the ninth knurled teeth when it joins the cam, $F_{s, 9}(l)$ stand for the shear force of the ninth knurled tooth in joining process, and so on.

Firstly, calculating the difference between the first tooth and the last tooth. This is eight times the friction force of single knurled tooth joining. So the $F_{s}$ and $F_{f}$ can be obtained using the Eq. 12 and joining force experiment data. For interference $0.15 \mathrm{~mm}$, $F_{s}$ is $0.87 \mathrm{KN}$ and $F_{f}$ is $6.23 \mathrm{KN}$. Ignoring the influence of experiment error, the joining force can be simplified as linear increase with the increase of joining length (as shown in the oblique dotted line in Fig. 3. The rising rate is about $0.55 \mathrm{KN} / \mathrm{mm}$ during joining process.

The experimental curves of static torsion strength are shown in Fig. 4 when the interference is $0.15 \mathrm{~mm}$. The curves could be divided into three stages: linear rising 
(elastic), nonlinear rising (plastic), and decline (failure).

The torsion speed is set as $10^{\circ} / \mathrm{min}$. The corresponding torsion angles of elastic deformation and failure were $1.15^{\circ}$ and $8^{\circ}$ for experimental values respectively. The cam begins to slip and lose efficacy when the torsion angle is greater than $8^{\circ}$. The maximum torsion is $654.2 \mathrm{Nm}$, which are much higher than the requirements of typical static torsion $200 \mathrm{Nm}$ [27]. The maximum torque is the connection strength of assembly camshaft.

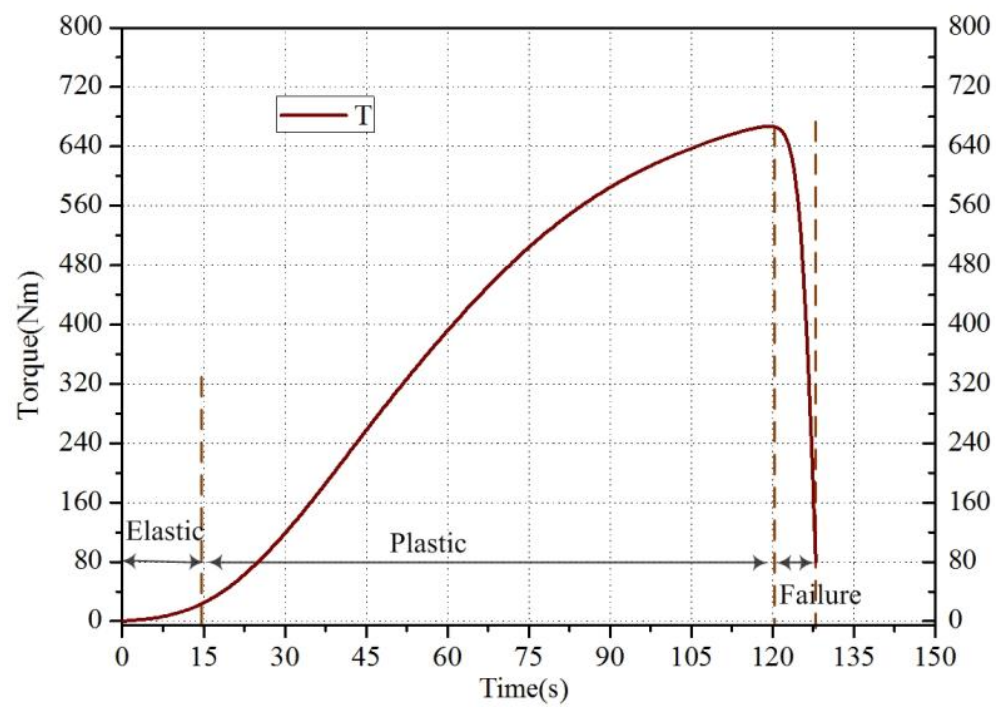

Fig. 4 Connection strength of 12\# experiment

Larger interference leads to higher joining force and higher connection strength as shown in Table 3. Joining force should be kept as low as possible for assembly accuracy. And greater torsion are desired for reliable connection. However, joining force and torsion increase with the increase of interference as we can assume.

When the interference is $0.05 \mathrm{~mm}, 0.1 \mathrm{~mm}, 0.15 \mathrm{~mm}, 0.2 \mathrm{~mm}$ and $0.25 \mathrm{~mm}$, the average maximum joining force is about $8.2 \mathrm{KN}, 12.1 \mathrm{KN}, 13.8 \mathrm{KN}, 17.0 \mathrm{KN}$ and 21.0 KN respectively. The corresponding torque is $380 \mathrm{Nm}, 562 \mathrm{Nm}, 613 \mathrm{Nm}, 669$ $\mathrm{Nm}$ and $689 \mathrm{Nm}$ respectively. The average joining force and connection strength for different interference group are shown as histogram in Fig. 5. From interference 0.05 $\mathrm{mm}$ to $0.1 \mathrm{~mm}$, the torque has a significant increase. while among the radial interference $0.1 \mathrm{~mm}$ to $0.25 \mathrm{~mm}$, the torque increased slowly. 


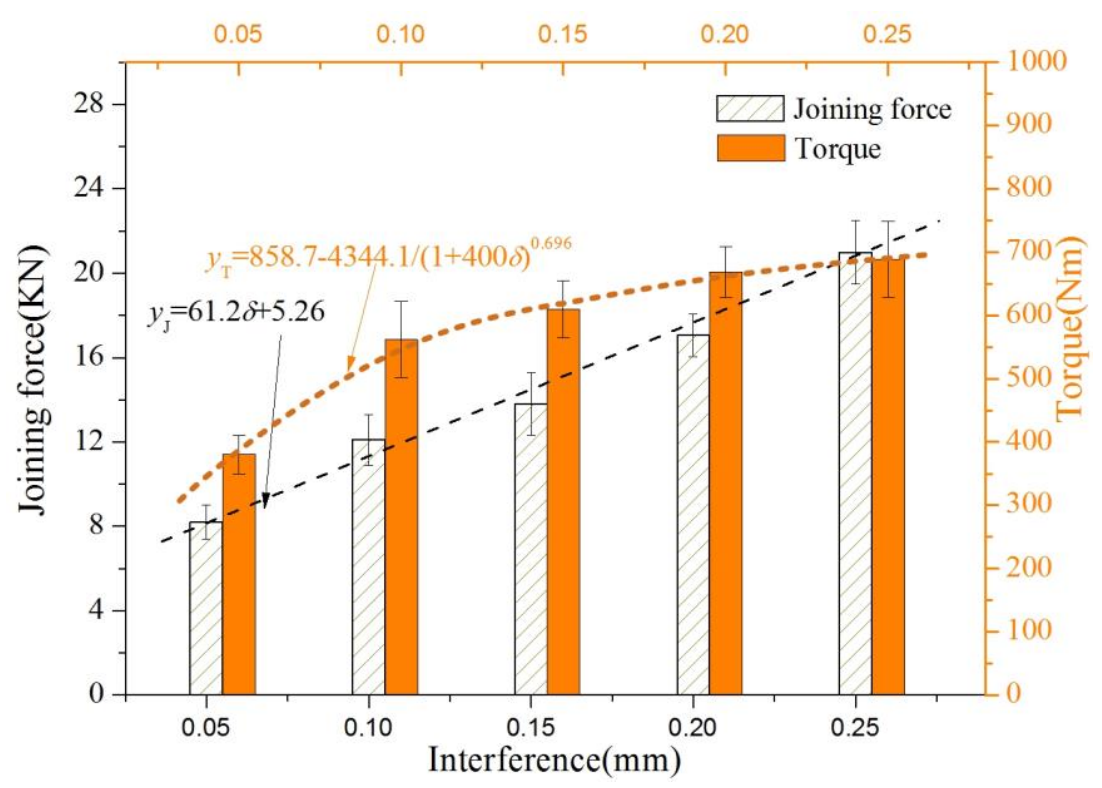

Fig. 5 Comparison of joining force and torque in different interference

The relationship between interference and joining force and torque can be expressed by fitting as:

$$
\begin{aligned}
& T=858.7-4344.1 /(1+400 \delta)^{0.696}, \\
& F=61.2 \delta+5.26
\end{aligned}
$$

Based on interference $0.05 \mathrm{~mm}$ group, the relative growth rate of connection strength is $\left(T_{0.25}-T_{0.05}\right) / T_{0.05}=81.3 \%$ for interference $0.25 \mathrm{~mm}$. And the relative growth rate of joining force is $\left(F_{0.25}-F_{0.05}\right) / F_{0.05}=156.1 \%$ for interference $0.25 \mathrm{~mm}$. The relative growth rate of connection strength is lower than that of joining force when the interference increased. This means increasing interference unilaterally is not a good way to improve the connection strength.

\subsection{Metal plastic deformation of knurled shaft}

Fig. 3 shows the morphology of 12\# camshaft after joining. The knurled teeth are pushed down to the cam inner surface. The tube is embedded into the groove structure of the cam and the knurled teeth is squeezed severely as the experiment and FEM results shown in Fig. 6a and 6b. The contact between the tube and the cam is discontinuous because of the inside splined profile of the cam. This kind of connection can provide additional connection strength under twist service for camshaft. 
Fig. 6c revealed that the geometric configuration of the cam remain unchanged after joining. This result proved that the rigidity assumption of cam is feasible in the FEM model. When continuously increasing the interference to $0.3 \mathrm{~mm}$, the cam will be broken as show in Fig. 6d. Therefore, large interference between cam and steel pipe should be avoided.
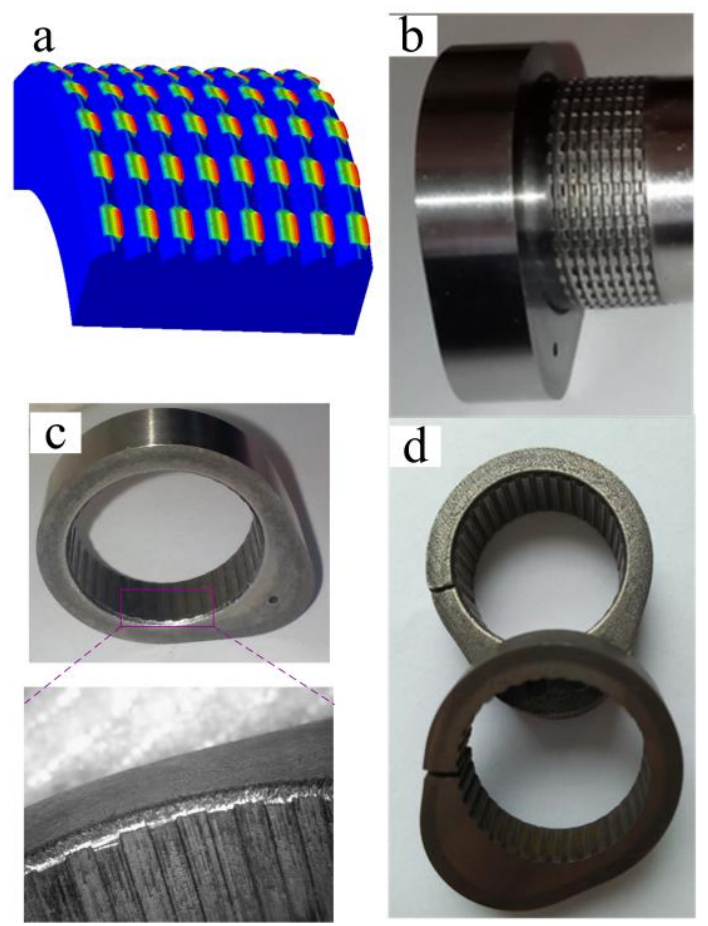

Fig. 6 Experiment and FEM morphology of camshaft after joining. a FEM tooth profile of the tube. $b$ Experiment tooth profile of the tube. $c$ Experiment profile of the tube. $d$ Failure cam of interference $0.3 \mathrm{~mm}$

Metal streamline of the knurled teeth along axial direction and the radial direction are shown in Fig. 7. From radial section of the camshaft in Fig. 7b, we can see that tooth is squeezed to flat by cam and materials of the tube are pushed into the valley of the teeth. The knurled teeth of tube engaging with the grooves of the cam are formed in the axial direction and the radial direction when the joining is completed. Knurled teeth of the tube can be divided into three zones according to metal deformation characteristics as shown in the axial section of Fig 7c. 

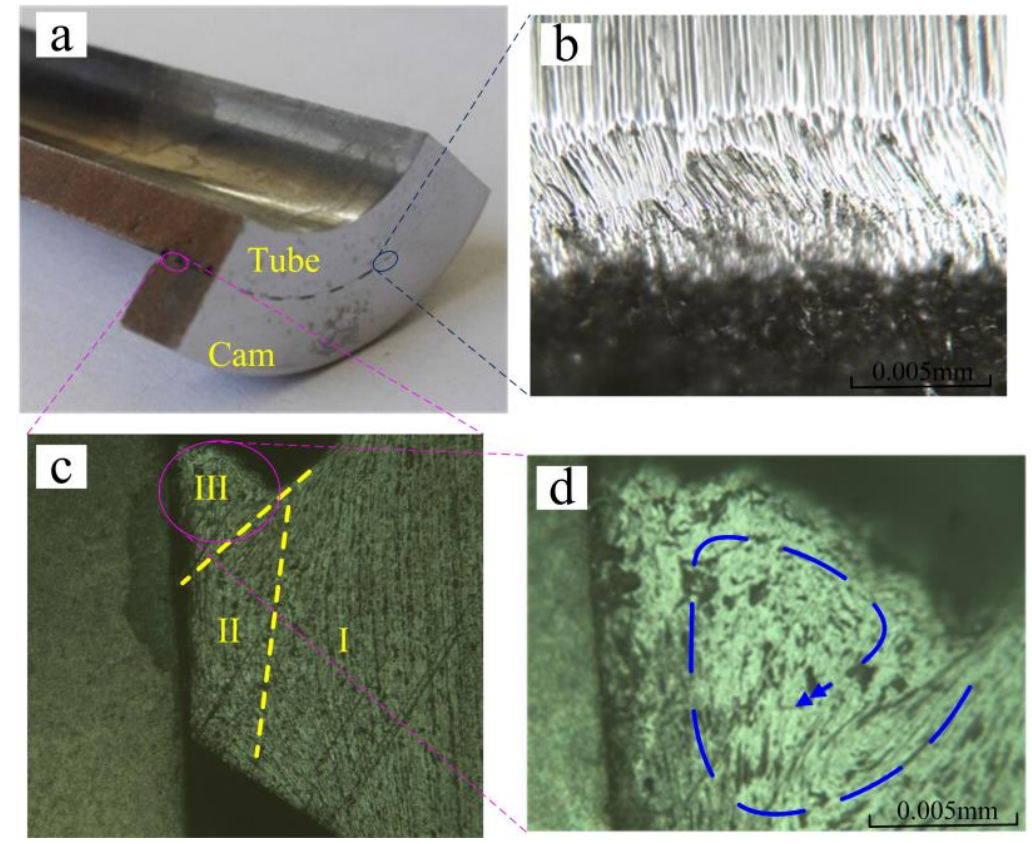

Fig. 7 Microstructure of metal streamline. a Cut camshaft. b Radial section of camshaft. c Axial section of camshaft. $\mathrm{d}$ Top of knurled tooth after joining

Zone I is elastic deformation zone. Metal streamline of this zone is almost parallel to the axis direction without plastic deformation. This is supported by FEM results in Fig. 6. Zone II is plastic squeeze zone. The knurled tooth is compressed tightly to the inside surface of the cam. It is extruded in the axis direction as shown in Fig. $7 \mathrm{~b}$ and $7 \mathrm{c}$. Zone III is the plastic bending zone. The material in Zone III tends to flow towards the free valley between neighboring teeth of tube. Triangular knurled teeth gradually turn over under the extrusion action of cam. Top material of knurled tooth gradually formed an inverted triangle shape finally as shown in Fig. 7d.

\subsection{Stress and strain}

The stress, displacement and plastic strain nephogram after joining are shown in Fig. 8. As represented in Fig. 8a, the highest compressive Mises stress $587 \mathrm{MPa}$ is observed on the top portion of the tooth. It exceeds the yield limit of tube material, indicating that plastic deformation occurs in some areas. Residual stress is over 300 MPa for most regions of the knurled teeth.

The maximum plastic strain regions are located in the central part of the knurled tooth. The maximum equivalent plastic strain(PEEQ) reached 6.49. This means 
material yield and hardening severely in the top half of the knurled teeth. No obvious plastic strain is observed under the depth of $0.5 \mathrm{~mm}$ from the top of the tooth.

The maximum displacement in $Y$ direction is $0.458 \mathrm{~mm}$, which correspond to tooth material sliding displacement in axial direction. And the maximum displacement of $0.156 \mathrm{~mm}$ in $\mathrm{Z}$ direction corresponds to interference extrusion in radial direction. This is consistent with the interference value of 12\# experiment.
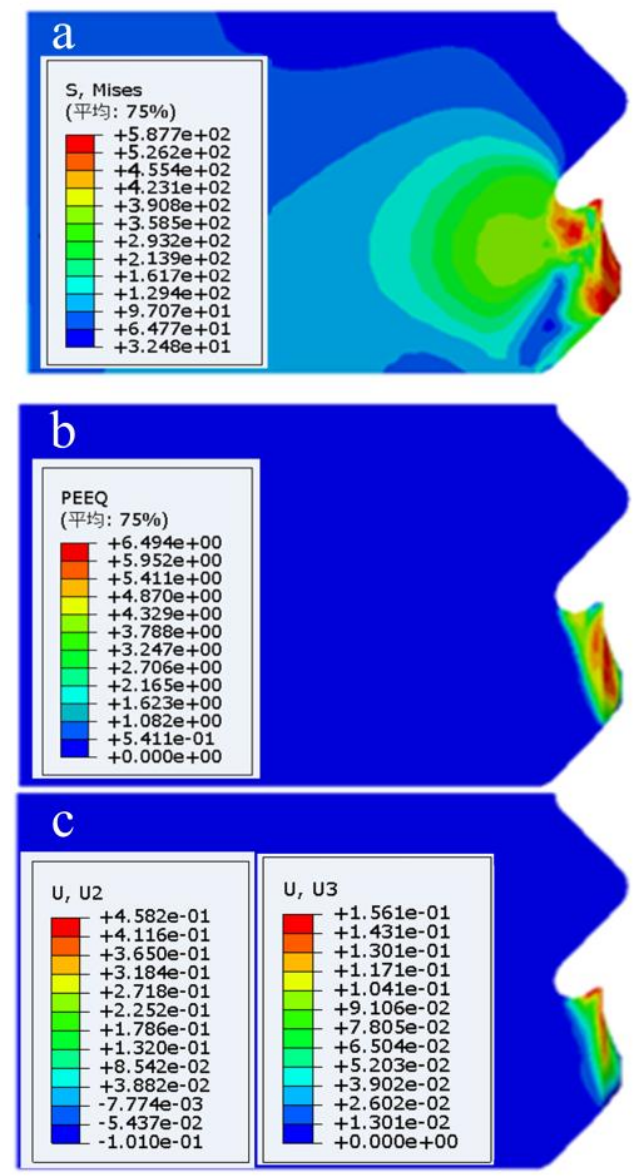

Fig 8 Stress, strain and displacement of knurled tooth after joining

\section{Conclusion}

In this investigation, the aim was to analyse the joining process and torque of interference assembled camshaft with knurled cam and tube. The experiment is carried out, in which the cam is made of E355 and the tube is made of GCr15.

(1) Joining force and connection are caused by the combined action of friction and shear. In order to obtain the influence of interference on the joining force and 
connection strength, calculation formulas of joining force and connection strength are analyzed based on the thick wall cylinder model and plastic mechanics.

(2) There is a positive correlation between the interference and joining force, connection strength. Joining force wavelike rises with joining length. It is caused by the knurled teeth. The relationship between the joining force, torque and the interference of the camshaft is established by linear fitting and exponential fitting. The relative growth rate of connection strength is lower than that of joining force. In order to avoid expansion crack of the cam, the interference cannot be greater than a certain value $0.3 \mathrm{~mm}$.

(3) Experiment and FEM results reveal that mosaic connection is formed between tube and cam. Material of knurled tooth is squeezed to flat with plastic deformation. Metal streamlines show that triangular knurled teeth turn over and formed an inverted triangle shape. Residual stress $587 \mathrm{MPa}$ is observed on the top portion of the tooth, and the maximum PEEQ reached 6.49 after joining.

(4) The limitation of this study is that influence of knurling process on hardening of knurled tooth is ignored in FEM.

\section{Declaration}

\section{Ethical Approval}

Ethics approval was not required for this research.

\section{Funding}

This work was funded by Natural Science Foundation of Shandong Province (No. ZR2016EEP04).

\section{Competing interests}

The authors declare that they have no competing financial interests or personal relationships that could have appeared to influence the work reported in this paper.

\section{Availability of data and material}


The datasets used or analysed during the current study are available from the corresponding author on reasonable request.

\section{Authors' contributions}

The author' contributions are as follows: Xiaoming Huang was in charge of the whole trial and designed the study; Xiaoming Huang and Wentao You wrote and edited the manuscript; Weitao Sun and Yuqian Wang assisted with sampling and laboratory analyses; Xiaoliang Liu and Yucan Wang provided guidance and discussion in theory; Jin Xing and Hailin Bi performed the experiments. All authors read and approved the final manuscript.

\section{Consent to Participate}

Not applicable

\section{Consent to Publish}

This work has not been submitted and not been published previously, is not under consideration for publication elsewhere, and is approved and wish to be considered for publication in The International Journal of Advanced Manufacturing Technology by all authors.

\section{References}

[1] Bonatesta F, Altamore G, Kalsi J, Cary M (2016) Fuel economy analysis of part-load variable camshaft timing strategies in two modern small-capacity spark ignition engines. Applied Energy 164: 475-491. https://doi.org/ 10.1016/j.apenergy.2015.11.057

[2] André H, Antal D, Sebastian G, Tim O, Ralf, Behrens BA, Christoph H, Klaus D, Sebastian T (2020) Integrated computational product and production engineering for multi-material lightweight structures. Int J Adv Manuf Technol 110(9):2551-2571. https://doi.org/ 10.1007/s00170-020-05895-6

[3] Paolo C, Daniele L, Michele G (2018) An ecodesign approach for the lightweight engineering of cast iron parts. Int $J$ Adv Manuf Technol 
99(9):2365-2388. https://doi.org/ 10.1007/s00170-018-2649-7

[4] Morphy G, Neelwarne A (2007) Weight reduction opportunities through innovative hydroforming case of one piece frame rails \& hollow camshafts. National Conference on Sheet Metal Forming Ontario Canada.

[5] Duque DA, Souza P, Savoy M, Valentina G (2011) Analysis of the contact pressure between cams and roller followers in assembled camshafts. SAE BRASIL International Congress and Exhibition Sao Paulo Brazil.

[6] Przybylski W, Wojciechowski J, Klaus A, Marre M, Kleiner M (2008) Manufacturing of resistant joints by rolling for light tubular structures. Int $\mathrm{J} \mathrm{Adv}$ Manuf Technol 35:924-934. https://doi.org/ 10.1007/s00170-006-0775-0

[7] Zhang P, Kou SQ, Li C, Kou ZM (2018) Joint mechanism and prediction of strength for a radial knurling connection of assembled camshaft using a subsequent modeling approach. SAE Int J Engines 3(11):301-310

[8] Mori K, Bay N, Fratini L, Micari F, Tekkaya AE (2013) Joining by plastic deformation. CIRP Ann Manuf Technol 62:673-694

[9] Zhao J, Wang JX, Yu C, Tang SQ, Yao J (2019) Influence of radial interference on torque capacity of shrink-fit camshaft. Advances in Mechanical Engineering 11(4): 1-10. https://doi.org/ 10.1177/1687814018817640

[10] Christian W, Steven TW, Michael M, Jens N, Verena PA, Erman T, Wolfgang $\mathrm{T}$ (2011) Influence of groove characteristics on strength of form-fit joints. Journal of Materials Processing Technology. 211:925-935. https://doi.org/ 10.1016/j.jmatprotec.2010.08.004

[11] Kleditzsch S, Lätzer M, Awiszus B, Leidich E (2014) Numerical investigation of knurled shaft-hub connections and especially of the joining process. Mater Sci Forum 773(18):18-27

[12] Lätzer M, Kleditzsch S, Leidich E, Awiszus B (2012) Analytical and numerical computation of knurled interference fits in comparison with experimental stud-ies. Proceedings of 11th YSESM Brasov Romania

[13] Zhang P, Kou SQ, Lin BJ, Wang YM (2015) Optimization for radial knurling connection process of assembled camshaft using response surface method. 
Int J Adv Manuf Technol 77:653-661. https://doi.org/ 10.1007/s00170-014-6486-Z

[14]Sen S, Aksakal B (2004) Stress analysis of interference fitted shaft-hub system under transient heat transfer conditions. Mater Design 25: 407-417. https://doi.org/ 10.1016/j.matdes.2003.11.009

[15]Cao R, Li L, Zhang J, Chen JH (2010) Internal stress analysis of interference fittings of TiAl turbine shaft and K418 alloy sleeve. Phys Test Chem Anal 46: $552-556$

[16]Luo Y, Wang XD, Wang MX, Tan DB, Zhang T, Yang YC (2013) A force/stiffness compensation method for precision multi-peg-hole assembly. Int J Adv Manuf Technol 67:951-956. https://doi.org/ 10.1007/s00170-012-4539-8

[17] Kim J, Kim SW, Park HJ, Kang BS (2006) A prediction of bursting failure in tube hydroforming process based on plastic instability. Int J Adv Manuf Technol 27(5):518-524. https://doi.org/ 10.1007/s00170-004-2204-6

[18] Song WJ, Kim SW, Kim J, Kang BS (2005) Analytical and numerical analysis of bursting failure prediction in tube hydroforming. Journal of Materials Processing Technology 164:1618-1623.

[19] Watson M, Long H, Lu B (2015) Investigation of wrinkling failure mechanics in metal spinning by Box-Behnken design of experiments using finite element method. Int J Adv Manuf Technol 78(5):981-995. https://doi.org/ 10.1007/s00170-014-6694-6

[20] Zhao YH, Li QH, Li FG, Wang CP (2012) Research on grading expanding process and crack for rings. China Metalforming Equipment \& Manufacturing Technology 1:79-83

[21] Ben NY, Zhang DW, Liu N, Zhao XP, Guo ZJ, Zhang Q, Zhao SD (2017) FE modeling of warm flanging process of large T-pipe from thick-wall cylinder. Int $\mathbf{J} \mathrm{Adv}$ Manuf Technol 93: 3189-3201. https://doi.org/ 10.1007/s00170-017-0739-6

[22]Stefan K, Michael L, Birgit A, Erhard L (2014) Numerical investigation of knurled shaft-hub connections and especially of the joining process. Materials Science Forum 773: 18-27. https://doi.org/ 10.4028/www.scientific.net/MSF.773-774.18

[23] Ran JQ, Zhang GQ, Chen GP, Wang JL, Deng BL, Kuz'min M P, Xu T, 
Gong F (2020) A multi-strain-rate damage model on fracture prediction in single-point diamond turning process. Int J Adv Manuf Technol 110(9):2753-2765. https://doi.org/ 10.1007/s00170-020-06023-0

[24] Guo X, Xing H, Xu Y, Elaty AA, Ma Y, Zhao Y, Zhang S (2018) U-R relationship prediction method for aluminum alloy circular tube free-bending process based on sensitivity analysis of material parameters. Int J Adv Manuf Technol 99(5):1967-1977. https://doi.org/ 10.1007/s00170-018-2614-5

[25]Wen BC, Huang WH, Tan JR (2010) Mechanical design manual. Machinery Industry Press, Beijing

[26]Yang GM, Coquille JC, Fontaine JF, Lambertin M (2002) Contact pressure between two rough surfaces of a cylindrical fit. J Mater Process Technol 123:490-497. https://doi.org/ 10.1016/S0924-0136(02)00139-5

[27] Pierre B, Salvator N, Trasorras JR (2000) Assembled Camshaft with Sintered Cam Lobes: Torsional Fatigue Strength and Wear Performance. SAE 2000 World Congress Detroit MI 
Figures

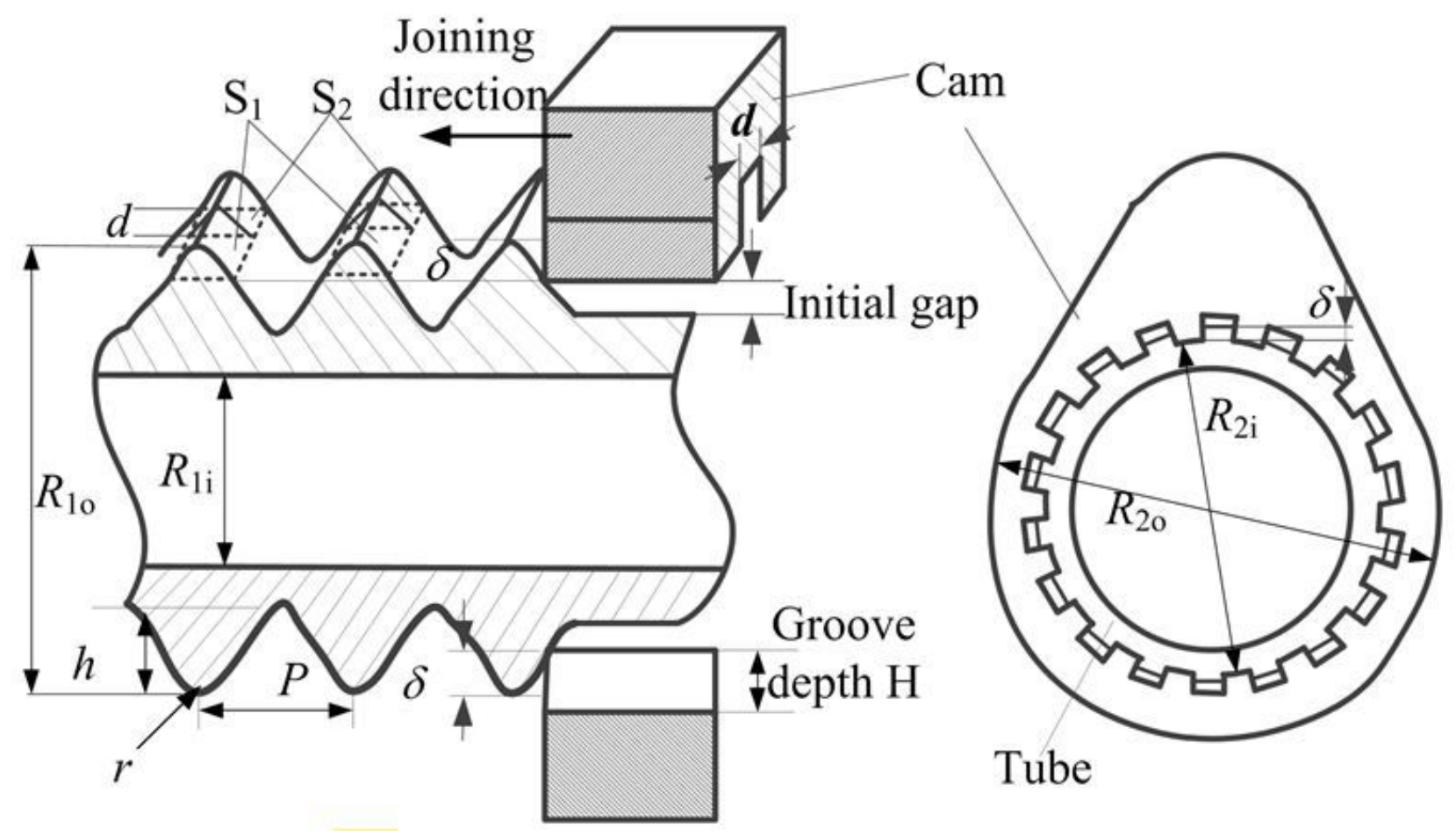

Figure 1

Axial and radial section of camshaft 


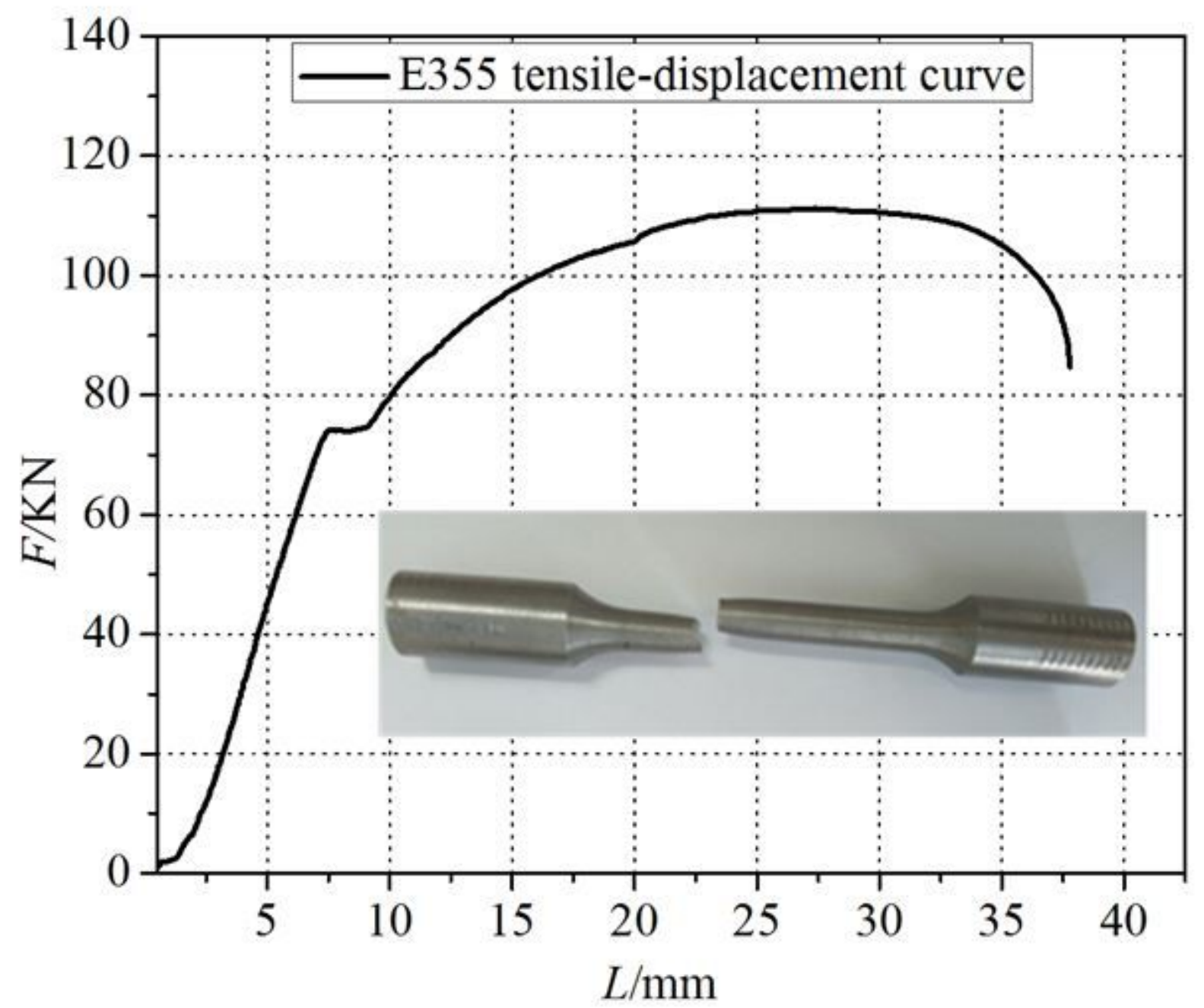

Figure 2

Engineering load / displacement curve 


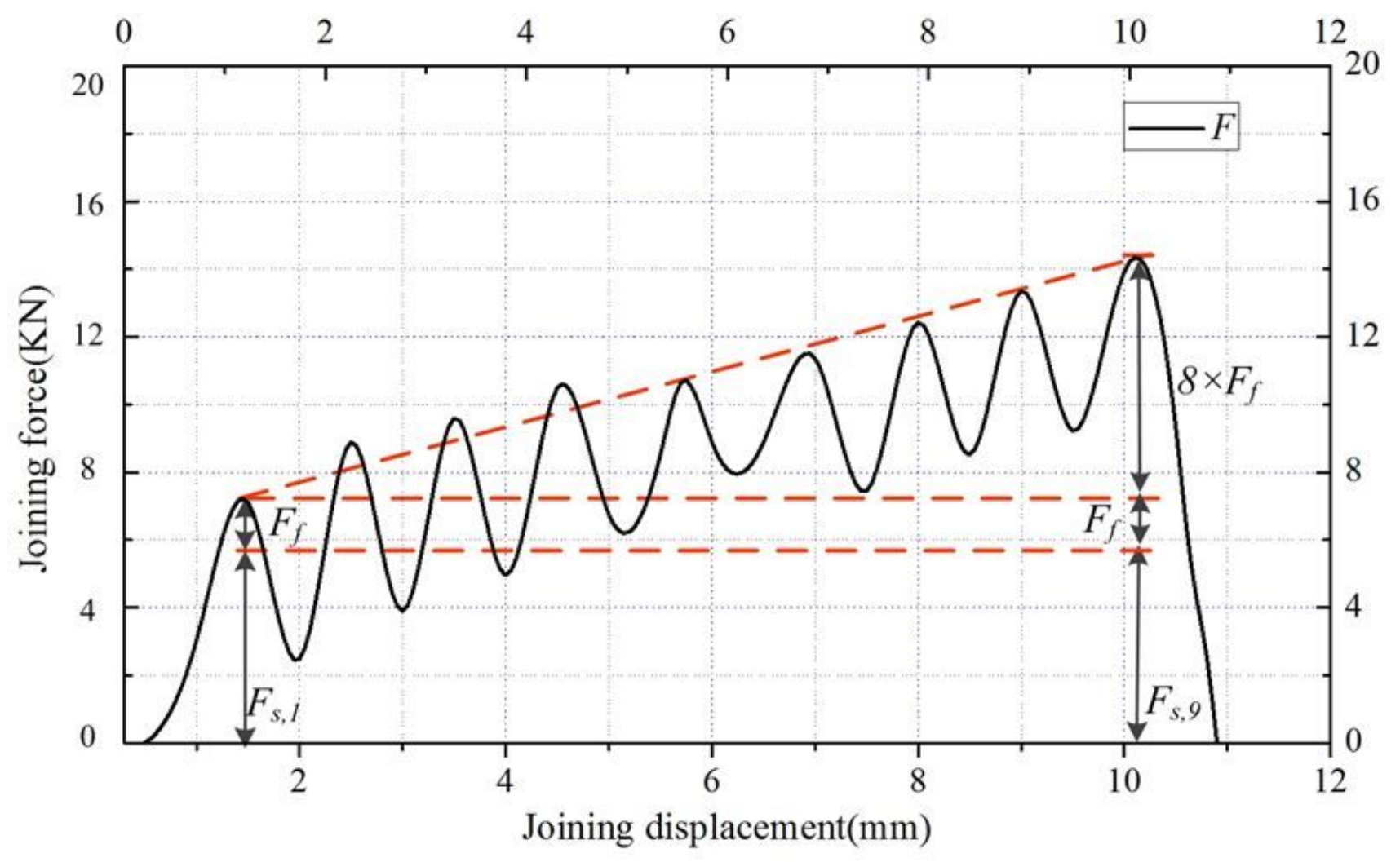

Figure 3

Joining force curve of 12\# experiment 


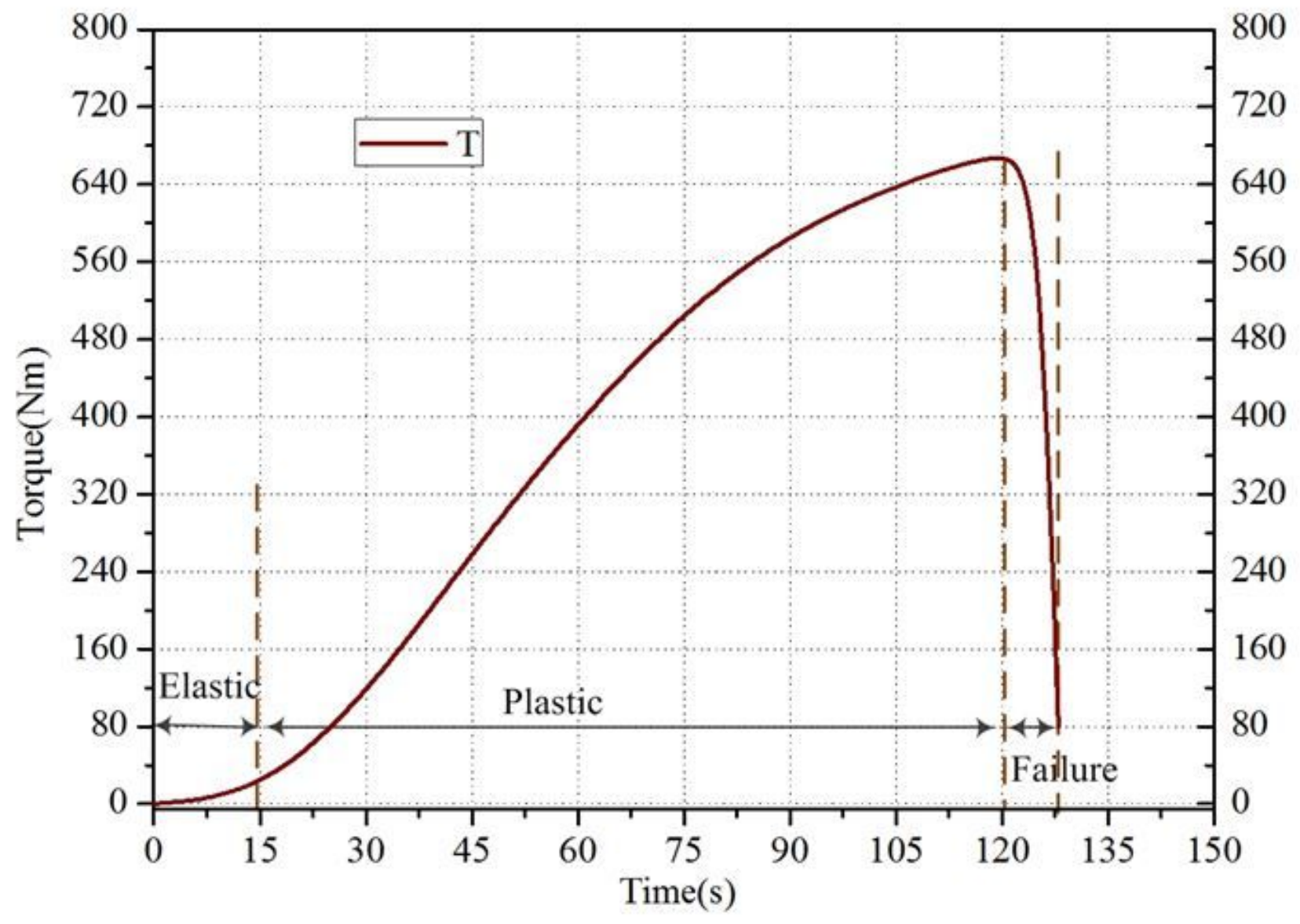

Figure 4

Connection strength of $12 \#$ experiment 


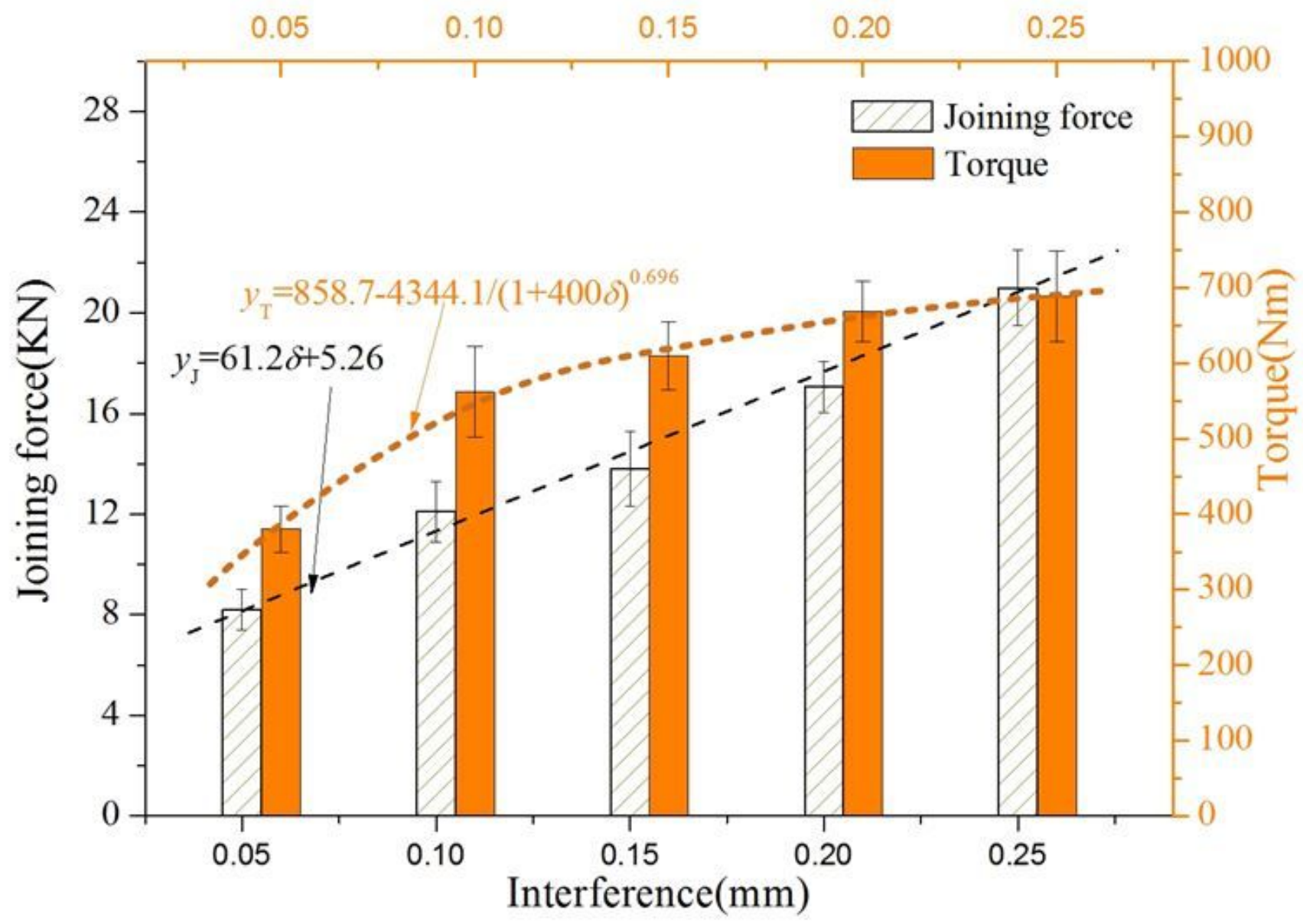

Figure 5

Comparison of joining force and torque in different interference 

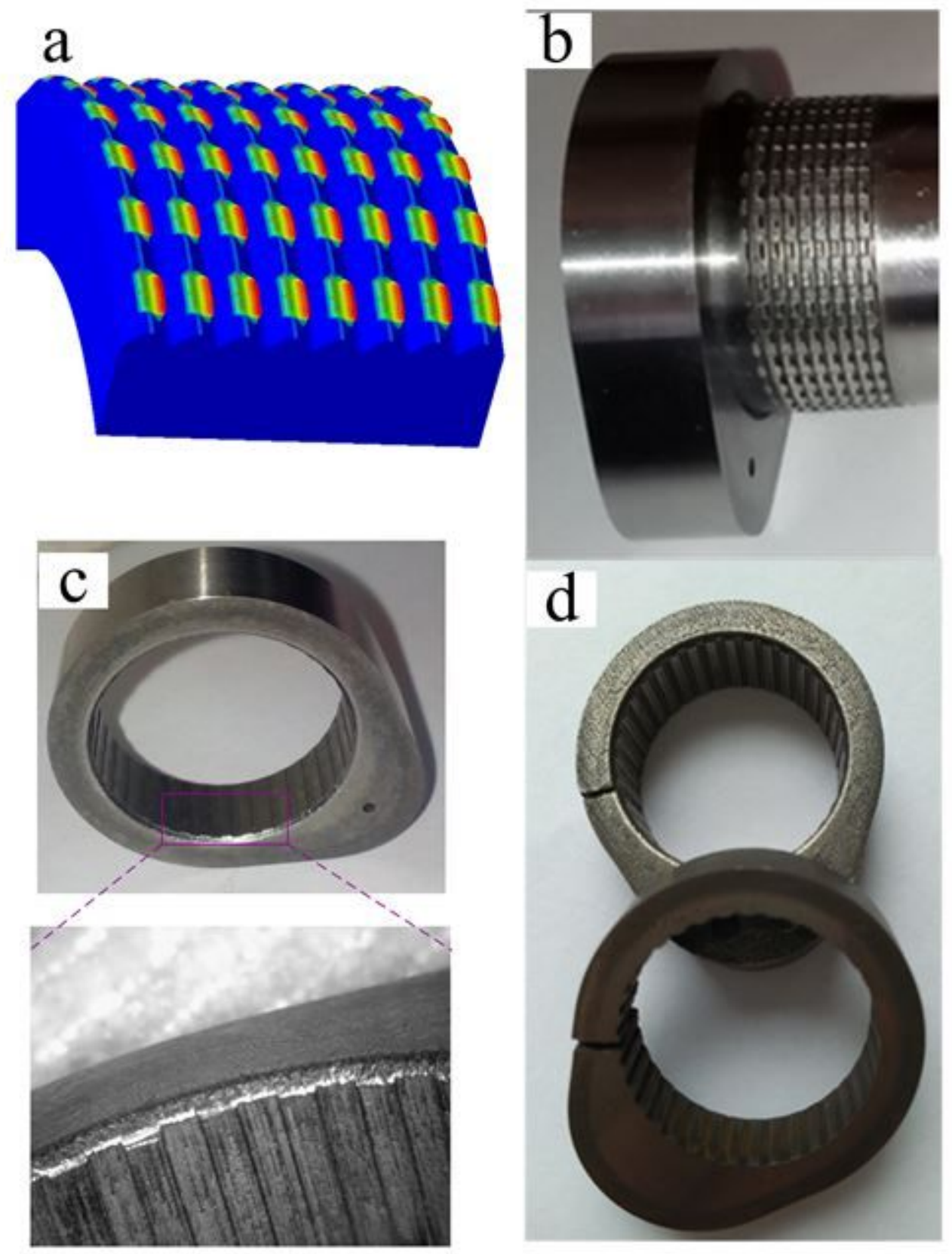

\section{Figure 6}

Experiment and FEM morphology of camshaft after joining. a FEM tooth profile of the tube. $b$ Experiment tooth profile of the tube. $c$ Experiment profile of the tube. $d$ Failure cam of interference $0.3 \mathrm{~mm}$ 


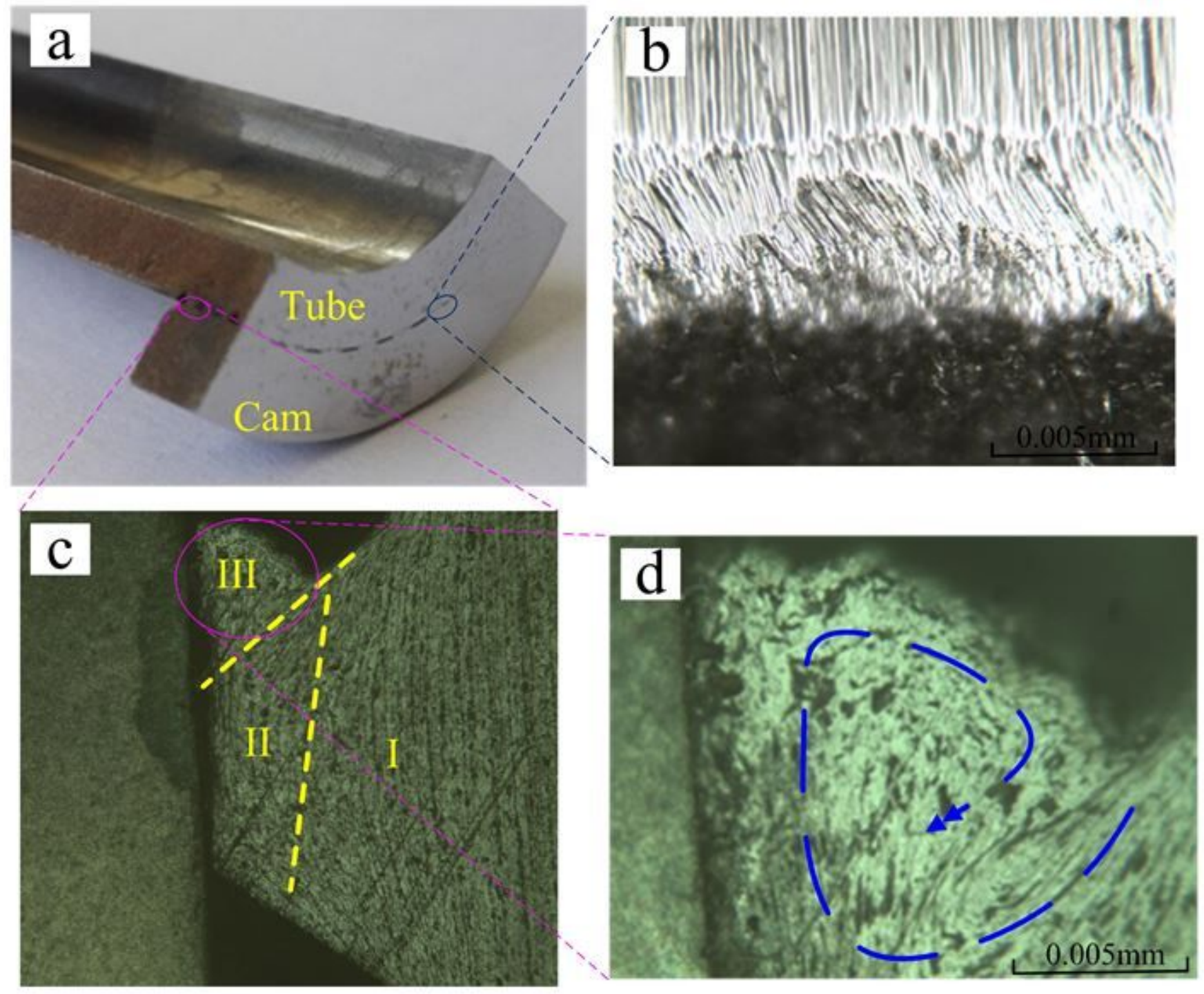

Figure 7

Microstructure of metal streamline. a Cut camshaft. b Radial section of camshaft. c Axial section of camshaft. $d$ Top of knurled tooth after joining 

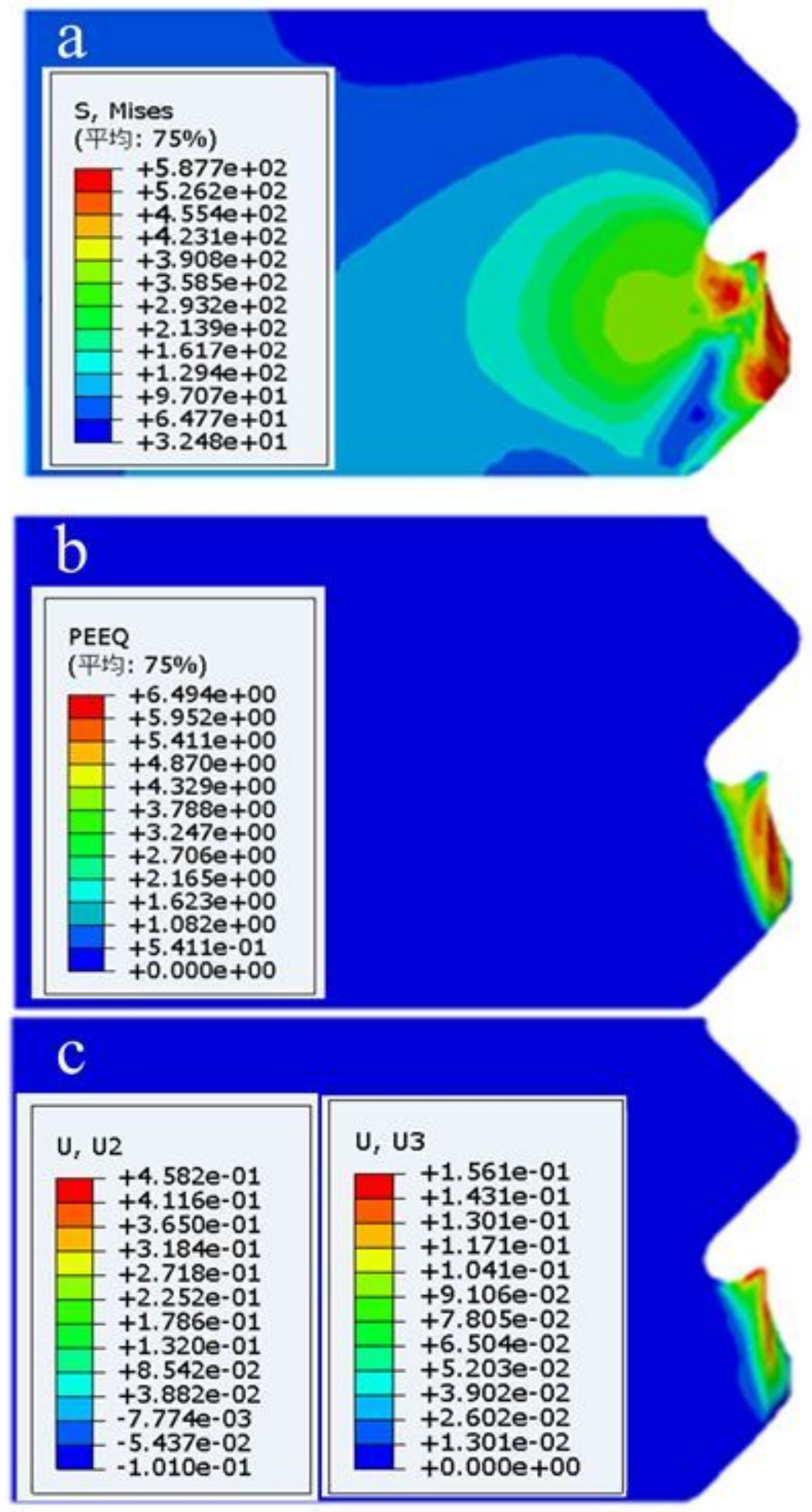

Figure 8

Stress, strain and displacement of knurled tooth after joining 